\title{
EFICACIA BIOLÓGICA DE CUATRO BIONEMATICIDAS EN EL COMBATE DE NEMATODOS (Pratylenchus sp. $y$ Meloidogyne sp.) QUE AFECTAN AL CULTIVO DE ÑAME (Dioscorea rotundata)
}

\author{
Ricardo Piedra Naranjo ${ }^{1}$; Jorge Meckbel Campos²; \\ Edgar Aguilar Brenes; ${ }^{3}$ Marcos Brenes Chavarría ${ }^{4}$
}

\begin{abstract}
RESUMEN
La investigación se realizó en la Estación Experimental Diamantes del Instituto Nacional de Innovación y Transferencia en Tecnología Agropecuaria (INTA), cantón Pococí, provincia de Limón, Costa Rica. Según Holdridge la zona tiene un Bosque Tropical Húmedo, con una precipitación de $4.000 \mathrm{~mm}$ anuales, una altura de $249 \mathrm{msnm}$, un promedio de temperatura mínima de $24^{\circ} \mathrm{C}$, una máxima de $29^{\circ} \mathrm{C}$, un suelo fértil, suelto y profundo. Se utilizó un diseño de Bloques Completos al Azar con cinco repeticiones y cinco tratamientos. En el análisis de los datos se aplicó el programa SAS versión 6,11, con una separación de medias de Tuckey al $5 \%$. Los tratamientos nematicidas utilizados fueron: Extractos naturales de algas (Laminaria digitata, Laminaria hyperborea, Mucus serratus y Ascohyllum nodosun, Citoquininas), Bacteria Burkhorderia tipo Wisconsin, y hongos Arthrobotris oligospora, A. botryospora y Dactyllela brochophaga, el hongo Paecilomyces lilacinus y Testigo Absoluto, sin nematicida. Los nematicidas biológicos se aplicaron con una bomba de espalda marca Carpi, sin boquilla y sin presión dirigida hacia el suelo, junto con la semilla al momento de la siembra y la segunda aplicación se realizó a los cuatro meses aplicando los nematicidas a la base del tallo de la planta en cada tratamiento. Se realizaron cuatro muestreos durante el ciclo del cultivo.
\end{abstract}

Se determinó en $100 \mathrm{~g}$ de raíz, suelo y cáscara del tubérculo, la presencia de tres géneros importantes de nematodos fitoparásitos en el cultivo de ñame, Meloidogyne sp, Helicotylenchus $s p$ y Pratylenchus $s p$, este último el de mayor número de larvas en los $100 \mathrm{~g}$ de cáscara evaluados al final de la cosecha. La menor cantidad de larvas del género Meloidogyne sp se obtuvo en los tratamientos con extractos naturales de algas y de la bacteria Burkhorderia tipo Wisconsin, con una población menor a 7.000/100 g de cáscara del tubérculo. En la evaluación de Pratylenchus sp. en $100 \mathrm{~g}$ de raíz se observaron diferencias estadísticas con el respecto a los demás tratamiento. La variable de peso en gramos de cuatro plantas de ñame por cada tratamiento, no presentó diferencias significativas. El porcentaje de sanidad del tubérculo presentó diferencias estadísticas según análisis de Tukey al $5 \%$, donde los tratamientos con extractos Sincocin 0,55 SL y Nemaut 0,67 PM mostraron una mejor sanidad.

Palabras claves: Pratylenchus $s p$, Meloidogyne $s p$, nematicidas biológicos, nematodos fitoparásitos, saprófitos, Dioscorea.

\footnotetext{
${ }^{1}$ Instituto Nacional de Innovación y Transferencia en Tecnología Agropecuaria. INTA. Costa Rica. Estudiante Doctorado en Ciencias Naturales para el Desarrollo (DOCINAE). Teléfono: (506)2231-5055.

2 Instituto Nacional de Innovación y Transferencia en Tecnología Agropecuaria. INTA. Costa Rica. Técnico en Nematología. Teléfono: (506)2231-5055.

${ }^{3}$ Instituto Nacional de Innovación y Transferencia en Tecnología Agropecuaria. Pococí INTA. Costa Rica. Investigador Ñame. Teléfono(506)2710-6086.

${ }^{4}$ Instituto Nacional de Innovación y Transferencia en Tecnología Agropecuaria. Pococí. INTA. Costa Rica. Asistente. Teléfono (506)2710-6086.
} 


\section{INTRODUCCIÓN}

El cultivo de ñame pertenece al orden Dioscoreales, a familia Dioscoreaceae la cuál contiene seis géneros pero Dioscorea es el más importante con 600 especies identificadas, solamente 12 especies son comestibles (Melgar 2006). Este cultivo es una de las raíces comestibles de mayor potencial económico y alimenticio que produce Costa Rica. Se cultiva tanto para consumo nacional como para la exportación a mercados como New York y Florida. Dentro de las especies, la que más se cultiva es la variedad Dioscorea trífida. Esta especie es originaria de la zona Tropical de América, sus hojas son divididas entre tres o cinco lóbulos, el tallo es anguloso y alado, produce varios tubérculos como la papa. También se cultiva la especie Dioscorea alata, con fines de exportación, aunque en menor grado que la especie $D$. trífida. Relativamente se tiene poco conocimiento sobre el cultivo de ñame y es quizá lo que ha impedido el aumento de áreas en Costa Rica; no obstante, sus rendimientos son altos y puede generar fuertes ganancias si se tiene un seguimiento agronómico durante el ciclo del cultivo (Aguilar 1991).

El cultivo de ñame no escapa al ataque de plagas y enfermedades; donde se destaca el nematodo fitoparásito Pratylenchus $s p$. Los nematodos producen en la cáscara del tubérculo, agrietamiento y apariencia carbonosa así como daños físicos tales como: deformaciones, agallas; que lo hacen inaceptable para la exportación (Aguilar 1991). Las heridas provocadas por estos nematodos en los tubérculos son puntos de entrada de una serie de enfermedades secundarias, que aceleran su deterioro (Aguilar 1992). En el caso de ñame (Dioscorea sp.), la diseminación de Pratylenchus $s p$, está muy ligada al incremento de las actividades culturales; preparación de terreno y al constante paso de la gente que hacen que la plaga se propague rápidamente abarcando gran parte del cultivo. El otro género reportado y de importancia en el cultivo de ñame (Dioscorea sp.) es precisamente Meloidogyne sp. Este género en cultivos como café afecta el sistema radicular produciendo nodulaciones; que llegan a afectar las cosechas, reduciéndolas hasta en un $40 \%$, provocando gran impacto en la producción (Ramírez 1994).

Una forma de control de nematodos es a través del control biológico o sea organismos que controlan nematodos. Dentro de los enemigos naturales de los nematodos fitoparásitos se encuentran: Hongos atrapadores: Capturan los nematodos por medio de redes adhesivas, hifas y anillos. Endoparásitos de nematodos: Son hongos que tienen esporas que se adhieren a la cutícula y luego germinan, formando tubos que penetran al cuerpo por las aberturas naturales. Los endoparásitos se caracterizan por tener pequeños conidios y los predadores tienen conidios e hifas atrapadoras, que hacen bastante efectivo su accionar en nematodos fitoparásitos. Parásitos de huevos, hembras y quistes: Los hongos que atacan huevos pueden reducir la multiplicación de los nematodos y la mayoría de los estudios con estos hongos han sido con nematodos enquistadores $y$ agalladores. Pueden ser parásitos obligados, como Caternaria auxiliaris, Nematophthora gynophila, parásitos facultativos como Verticilium sp, chlamydosporium, Dactylella oviparasitica y Paecilomyces lilacinus. Bacterias: Actúan en dos formas, una acción parasítica y otra química. Nematodos Depredadores: Existen nematodos que controlan nematodos fitoparásitos. Entre estos se pueden citar: Aphelechidae, Diplogasteridade, Dorylaimidae y Monochidae (Carballo y Guaharay 2004).

En el tubérculo de ñame (Dioscorea $s p$ ) aparecen larvas de varios estadíos de los géneros Pratylenchus sp y Meloidogyne $s p$. Los huevos de estos géneros pueden sobrevivir en el suelo en forma latente o reproducirse con la presencia de raíces de otras plantas o malezas, que siempre se encuentran luego de una cosecha y esto hace que prevalezca como fuente de inóculo dispuesto a incrementarse en la siguiente siembra del cultivo (Crozzoli 1994). Estudios 
han revelado los efectos de la infección por nematodos y la interacción con hongos de suelo, especialmente algunos causantes de marchiteces como Fusarium $s p$ y Verticillium $s p$ y ha quedado establecido que muchos nematodos pueden ocasionar problemas fitopatológicos de manera independiente, al igual que ocurre con los hongos, bacterias y virus patógenos en muchos cultivos (Sanabria 1994).

Por muchos años se asumió que la herida causada por el nematodo al momento de penetrar es la causal principal de la enfermedad, pero hoy día se sabe que mecanismos más complejos están involucrados, tomando la infección del nematodo como el papel primario de la creación de la enfermedad. Dentro de estos complejos se ven envueltos nematodos y hongos como Fusarium y Verticillium causantes de marchiteces en las plantas (Beckman 1987).

Las lesiones provocadas por los nematodos fitoparásitos se convierten en vía de acceso a bacterias y hongos, que provocan la muerte del tejido radical. Esto interfiere con la translocación de agua y nutrientes por lo que la sintomatología expresada por la planta asemeja deficiencias nutricionales. Los daños causados por los nematodos fitoparásitos en las raíces reducen el peso de los racimos, provocan el volcamiento de plantas y afectan los retoños imposibilitando su venta o uso para siembras nuevas (Agrios 1997).

El ñame (Dioscorea sp.) es un cultivo de exportación en el cual no se permite aplicaciones de nematicidas químicos para el control de los nematodos fitoparásitos; por ello fue necesario evaluar el efecto de algunos bionematicidas por medio de análisis de muestras (suelo, raíz y cáscara de tubérculo) en el área experimental e incluyendo el diagnóstico de nematos de vida libre.

Por lo tanto, surge la necesidad de ejecutar esta investigación con el objetivo de evaluar la eficacia de cuatro productos biológicos de origen microbiano como una alternativa de manejo sostenible para los productores.

\section{MATERIALES Y MÉTODOS}

La investigación se ubicó en la provincia de Limón, Costa Rica, cantón de Pocosí, en la Estación Experimental los Diamantes, Instituto Nacional de Innovación y Transferencia en Tecnología Agropecuaria (INTA). Según Holdridge, la zona tiene un bosque tropical húmedo, con una precipitación de $4.000 \mathrm{~mm}$ anuales, una altura de $249 \mathrm{msnm}$, un promedio de temperatura mínima de $24^{\circ} \mathrm{C}$, una máxima de $29^{\circ} \mathrm{C}$, un suelo fértil, suelto y profundo. La siembra se realizó con semilla de ñame Cv. Dioscorea rotundata, la aplicación de los nematicidas biológicos se ejecutó utilizando bomba de espalda marca Carpi, sin boquilla dirigida hacia el suelo junto con la semilla al momento de la siembra y la segunda aplicación se realizó a los cuatro meses luego de la siembra a la base del tallo de la planta. El ensayo se ejecutó desde mes de Octubre 2004 hasta Diciembre 2005.

Se utilizó un diseño de Bloques Completos al Azar con cinco repeticiones y cinco tratamientos. En el análisis de los datos se utilizó el programa SAS versión 6,11 , con una separación de medias de Tukey al 5 $\%$. Los tratamientos nematicidas utilizados fueron: extractos naturales de algas (Laminaria digitata, Laminaria hyperborea, Mucus serratus y Ascohyllum nodosun) Citoquininas, Bacteria Burkhorderia tipo Wisconsin, y hongos Arthrobotris oligospora, A. botryospora y Dactyllela brochophaga, el hongo Paecilomyces lilacinus y Testigo Absoluto sin nematicida.

\section{Aplicación de productos}

Los nematicidas se aplicaron con una bomba de espalda marca Carpi, sin boquilla y sin presión dirigida hacia el suelo, junto con la semilla al momento de la siembra y la segunda aplicación se realizó a los cuatro meses aplicando los nematicidas a la base del tallo de la planta en cada tratamiento. Se realizaron cuatro muestreos durante el ciclo del cultivo. Se determinó en $100 \mathrm{~g}$ de raíz, suelo y cáscara del tubérculo la presencia 
de tres géneros importantes de nematodos fitoparásitos en el cultivo de ñame, Meloidogyne $s p$, Helicotylenchus sp y Pratylenchus sp, este último el de mayor número de larvas en los 100 gramos de cáscara evaluados al final de la cosecha.

\section{Muestreos, Procesamiento}

Se realizó un análisis de $100 \mathrm{~g}$ de suelo en el área experimental al inicio y a los treinta días después de la siembra en todos los tratamientos. Las muestras de suelo se analizaron por el método de flotación en azúcar en $100 \mathrm{~g}$. Las muestras de raíz y cáscara de los tubérculos se procesaron y diagnosticaron por tamizado y licuado utilizando $100 \mathrm{~g}$ de raíz y cáscara del tubérculo. La variable de la cáscara se efectuó al final del ciclo del cultivo, con una muestra de cuatro plantas de ñame y obteniendo el peso en gramos. Todas las muestras fueron observadas en microscopio de luz a 45X (Taylor 1963). El diagnóstico identificó poblaciones de nematodos de todos los géneros que se encontraron tanto en raíz y suelo como en cáscara del tubérculo.

\section{Análisis de las variables}

Para la evaluación de los bionematicidas se utilizó un diseño de bloques completos al azar con cinco tratamientos y cinco repeticiones (Cuadro 1). El análisis estadístico de las medias se llevó a cabo por medio del Análisis de Varianza con una prueba de separación de medias Tuckey al $5 \%$ Las variables analizadas fueron: cantidad de nematodos en $100 \mathrm{ml}$ de suelo y $100 \mathrm{~g}$ de raíz y cáscara. También se estimó un porcentaje de sanidad del tubérculo. Se analizó el comportamiento de los nematodos saprófitos o de vida libre con relación al efecto de los bionematicidas. Para evaluar el porcentaje de sanidad del tubérculo se utilizó una escala de severidad de 0 a $100 \%$.

Cuadro 1. Diseño de tratamientos y repeticiones en el campo. Diamantes, Guápiles. Costa Rica. 2004.

\begin{tabular}{lccccc}
\hline \multicolumn{7}{c}{ Repeticiones } \\
\hline Tratamientos & I & II & III & IV & V \\
\hline 1. Sincocin 0,55 SL & 2 & 5 & 1 & 3 & 4 \\
\hline 2. Microp 0,40 SL & 4 & 3 & 5 & 1 & 2 \\
\hline 3. Nemout 0,67 PM & 3 & 2 & 2 & 2 & 1 \\
\hline 4. Biostat 50 WP & 5 & 4 & 4 & 4 & 3 \\
\hline 5. Testigo Absoluto & 1 & 1 & 3 & 5 & 5 \\
\hline
\end{tabular}

Cuadro 2. Tratamientos, ingrediente activo y dosis producto comercial por hectárea. Diamantes, Costa Rica. 2004.

\begin{tabular}{ccc}
\hline Tratamientos & Ingrediente Activo & Dosis PC/ I/ ha \\
\hline 1.Sincocin 0,55 SL & $\begin{array}{c}\text { Extractos naturales de algas } \\
\text { (Laminaria digitata, Laminaria hyperborea, } \\
\text { Mucus serratus y Ascohyllum nodosun }) \\
\text { Citoquininas }\end{array}$ & \\
\hline 2.Microp 0,40 SL & $\begin{array}{c}\text { Bacteria Burkhorderia } \\
\text { (Pseudomonas) tipo Wisconsin }\end{array}$ & $2 \mathrm{I}$ \\
\hline 3.Nemout 0,67 PM & $\begin{array}{c}\text { Hongos Hipomycetes } \\
\text { Arthrobotris oligospora, } \\
\text { A. botryospora y } \\
\text { Dactyllela brochophaga }\end{array}$ & \\
\hline 4.Biostat 50 WP & Hongos Deuteromycete \\
& Paecilomyces lilacinus & \\
\hline 5.Testigo Absoluto & --- & \\
\hline
\end{tabular}




\section{RESULTADOS Y DISCUSIÓN}

En el análisis de suelo previo a la siembra se observaron los géneros Meloidogyne spy Pratylenchus $s p$. los cuales son considerados los más importantes en el cultivo de ñame y es indicador de daño producido en la formación del tubérculo (Cuadro 3).

Cuadro 3. Población de nematodos en $100 \mathrm{~g}$ de suelo, 30 días después de la siembra (DDS). Estación Experimental Diamantes. Guápiles, Costa Rica. Octubre 2004.

\begin{tabular}{c|c|c|c|c|c|c}
\hline $\begin{array}{c}\# \\
\text { Muestras }\end{array}$ & $\begin{array}{c}\text { Helicoty- } \\
\text { lenchus sp. }\end{array}$ & $\begin{array}{c}\text { Meloido- } \\
\text { gyne }\end{array}$ & $\begin{array}{c}\text { Pratrylen- } \\
\text { chus sp. }\end{array}$ & $\begin{array}{c}\text { Cricone- } \\
\text { moides sp. }\end{array}$ & $\begin{array}{c}\text { Tylen- } \\
\text { chus sp. }\end{array}$ & $\begin{array}{c}\text { Vida } \\
\text { libre }\end{array}$ \\
\hline 1 & 400 & 200 & 50 & 25 & 100 & 225 \\
\hline 2 & 450 & 175 & 75 & 25 & 75 & 300 \\
\hline 3 & 375 & 425 & 150 & 50 & 75 & 375 \\
\hline 4 & 425 & 450 & 100 & 38 & 75 & 325 \\
\hline
\end{tabular}

En el Cuadro 4, a los 30 días después de la siembra y de la primera aplicación, se realizó un muestreo de suelo en todas las parcelas. Los principales nematodos fitoparásitos encontrados en los muestreos fueron Meloidogyne sp., Helicotylenchus sp. y Pratylenchus sp.. La presencia de estos géneros de nematodos fitoparásitos hace prever que en el desarrollo del cultivo de ñame, tuvo o indujo a presentar problemas, no sólo por el daño que pudo ocasionar estos géneros por sí mismos, sino por la interacción que pudieron tener con otros patógenos del suelo como bacterias y hongos. Es muy normal, que en cultivos donde su producto final es el tubérculo, éste tenga la relación con otros organismos presentes en el suelo.

Cuadro 4. Resultado del análisis de $100 \mathrm{~g}$ de suelo 30 días después de la siembra. Guápiles, Costa Rica. Noviembre 2004.

\begin{tabular}{cccccc}
\hline Tratamientos & $\begin{array}{c}\text { Meloido- } \\
\text { gyne sp. }\end{array}$ & $\begin{array}{c}\text { Helicotylen- } \\
\text { chus sp. }\end{array}$ & $\begin{array}{c}\text { Pratrylen- } \\
\text { chus sp. }\end{array}$ & Saprófitos & $\begin{array}{c}\text { Cricone- } \\
\text { moides sp. }\end{array}$ \\
\hline 1.Sincocin 0,55 SL & 150 & 100 & 50 & 475 & 50 \\
\hline 2.Microp 0,40 SL & 175 & 150 & 75 & 450 & 75 \\
\hline 3.Nemout 0,67 PM & 75 & 250 & 50 & 250 & 125 \\
\hline 4.Biostat 50 WP & 75 & 125 & 75 & 650 & 75 \\
\hline 5. Testigo Absoluto & 125 & 175 & 50 & 575 & 125 \\
\hline
\end{tabular}

El muestreo en $100 \mathrm{~g}$ de raíz, realizado a los 90 días después de la siembra, diagnosticó géneros de nematodos fitoparásitos que pudieron ya iniciado su ciclo de vida infectar así las raíces del ñame (Cuadro 5). En este análisis se observaron dos géneros importantes (de nematodos fitoparásitos): Meloidogyne sp. y Pratylenchus sp..

Los tratamientos Nemout 0,67 y Sincocin 0,55 SL presentaron una menor población de nematodos fitoparásitos en las raíces de ñame. Las poblaciones más bajas del género Pratylenchus $s p$. ocurrieron con los tratamientos Sincocin 0,55 SL y Nemout 0,67 PM. Por el equilibrio de organismos del suelo las poblaciones de nematodos no tuvieron una cantidad similar entre géneros y esto es tomado como un proceso normal por la convivencia de organismos en el suelo. 
Cuadro 5. Población de nematodos de $100 \mathrm{~g}$ de raíz de ñame a los 90 días después de la aplicación. Estación Experimental Los Diamantes. Guápiles, Costa Rica. Enero 2005.

\author{
Tratamientos \\ 1.Cincosin 0,55 SL \\ 2.Microp 0,40 SL \\ 3.Nemout 0,67 PM \\ 4.Biostat 50 WP \\ 5.Testigo Absoluto
}

Meloidogyne sp.

1.500

4.000

2.000

4.000

15.000
Pratrylenchus sp.

3.000

30.000

1.000

35.000

5.000

En el Cuadro 6, se muestran los promedios del peso de cuatro plantas en cada tratamiento en el período de cosecha, así como el análisis estadístico. La variable de peso de tubérculos tiende a ser muy similar entre los tratamientos; y en la separación de medias no hay diferencias estadísticas según Tuckey al $5 \%$. Sin embargo, destacaron los tratamientos Microp 0,4 SL y Biostat 50 WP, con un mayor peso. Hay que considerar que el peso en los tubérculos no es importante en la exportación y semilla, en este caso, los productores, consideran la sanidad como característica más sobresaliente.

Cuadro 6. Peso promedio en g de 4 plantas de ñame en el momento de la cosecha para cada tratamiento. Estación Experimental Los Diamantes. Guápiles, Costa Rica. Diciembre 2005.

\begin{tabular}{ccccccc}
\hline & \multicolumn{7}{c}{ REPETICIONES } & \\
\cline { 2 - 6 } Tratamientos & I & II & III & IV & V & Medias \\
1.Sincocin 0,55 SL & 1.697 & 4.200 & 1.320 & 1.725 & 2.763 & $2.341,00(\mathrm{a})$ \\
2.Microp 0,40 SL & 4.547 & 1.278 & 3.211 & 2.173 & 3.625 & $2.966,80(\mathrm{a})$ \\
3.Nemout 0,67 PM & 2.090 & 1.686 & 4.350 & 1.560 & 2.732 & $2.483,60(\mathrm{a})$ \\
4.Biostat 50 WP & 3.762 & 3.400 & 1.064 & 2.445 & 3.600 & $2.854,20(\mathrm{a})$ \\
5. Testigo Absoluto. & 2.650 & 2.832 & 2.316 & 2.788 & 2.252 & $2.567,60(\mathrm{a})$ \\
\hline
\end{tabular}

Letras iguales no tienen diferencias estadísticas entre tratamientos en la separación de medias según Tuckey al 5 \%.

El cuadro 7, muestra los porcentajes de sanidad. En la sanidad del tubérculo intervinieron factores relacionados con la presencia de hongos, bacterias y los mismos nematodos fitoparásitos. Esto es muy importante porque la apariencia y sanidad de los tubérculos afectan su comercialización, tanto para el mercado local, así como para la exportación. En este cuadro resaltó el nematicida biológico Biostat 50 WP con diferencias estadísticas entre tratamientos, lo que demostró ser el mejor. 
Cuadro 7. Efecto de los tratamientos sobre el porcentaje de sanidad de ñame (D. rotundata) según tratamiento aplicado. Estación Experimental Los Diamantes. Guápiles, Costa Rica. Diciembre 2005.

\begin{tabular}{ccccccc}
\hline & \multicolumn{7}{c}{ REPETICIONES } & \multirow{2}{*}{ Medias } \\
\cline { 2 - 6 } Tratamientos & I & II & III & IV & V & Me (ab) \\
\hline 1.Sincocin 0,55 SL & 30 & 25 & 25 & 20 & 30 & $21(\mathrm{~b})$ \\
2.Microp 0,40 SL & 20 & 15 & 15 & 25 & 30 & $29,6(\mathrm{ab})$ \\
3.Nemout 0,67 PM & 28 & 30 & 20 & 35 & 35 & $34,4(\mathrm{a})^{\star}$ \\
4.Biostat 50 WP & 42 & 40 & 15 & 40 & 35 & $22(\mathrm{~b})$ \\
5. Testigo Absoluto & 35 & 30 & 10 & 15 & 20 &
\end{tabular}

*Letras diferentes tienen diferencias estadísticas entre tratamientos en la separación de medias según Tuckey al 5 \%.

En el Cuadro 8 se observaron poblaciones del género Meloidogyne sp en los tubérculos de ñame, el tratamiento Microp 0,4 SL mostró una tendencia a presentar menos larvas; esta cantidad pudo no afectar al tubérculo directamente; pero si pudo afectar con la interacción con otros patógenos de suelo como hongos y bacterias.

Cuadro 8. Cantidad de nematodos del género Meloidogyne sp. en $100 \mathrm{~g}$ de cáscara de ñame ( $D$. rotundata). Estación Experimental Los Diamantes Guápiles, Costa Rica, Diciembre 2005.

\begin{tabular}{ccccccc}
\hline & \multicolumn{7}{c}{ REPETICIONES } & Medias \\
\cline { 2 - 6 } Tratamientos & I & II & III & IV & V & 4.800 (a) \\
\hline 1.Sincocin 0,55 SL & 2.000 & 6.000 & 4.000 & 7.000 & 5.000 & $2.300(\mathrm{a})$ \\
2.Microp 0,40 SL & 1.000 & 1.000 & 3.000 & 3.500 & 3.000 & $6.800(\mathrm{a})$ \\
3.Nemout 0,67 PM & 17.000 & 3.000 & 8.000 & 4.000 & 2.000 & $5.900(\mathrm{a})$ \\
4.Biostat 50 WP & 2.000 & 8.000 & 9.000 & 6.000 & 4.500 & $3.300(\mathrm{a})$ \\
5.Testigo Absoluto & 4.000 & 2.000 & 2.000 & 4.500 & 4.000 & \\
\hline
\end{tabular}

Letras iguales no tienen diferencias estadísticas entre tratamientos en la separación de medias según Tuckey al 5 \%.

En el Cuadro 9 se mostró la cantidad de nematodos obtenidos en el análisis del laboratorio en $100 \mathrm{~g}$ de cáscara. Las medias del análisis estadístico evidenciaron un número bajo para el tratamiento Nemout 0,67 PM. Comparado con los otros tratamientos; se encontraron grandes diferencias. Es importante tomar en cuenta que poblaciones altas de larvas en los $100 \mathrm{~g}$ de cáscara de los tubérculos, el daño al cultivo es de una forma directa, considerando la interacción con otros patógenos del suelo. Los hongos nematófagos del producto Nemout 0,67 PM, lograron un efecto de control contra el género Pratylenchus sp. en este ensayo. 
Cuadro 9. Cantidad de nematodos del género Pratylenchus sp en $100 \mathrm{~g}$ de cáscara de ñame (D. rotundata) Estación Experimental Los Diamantes Guápiles, Costa Rica, Diciembre 2005.

\begin{tabular}{ccccccc}
\hline & \multicolumn{5}{c}{ REPETICIONES } & \\
\cline { 2 - 6 } Tratamientos & I & II & III & IV & V & Medias \\
1.Sincocin 0,55 SL & 46.000 & 11.000 & 62.000 & 2.000 & 27.000 & $29.600(\mathrm{ab})$ \\
2.Microp 0,40 SL & 51.000 & 6.000 & 28.000 & 2.000 & 26.000 & $22.600(\mathrm{ab})$ \\
3.Nemout 0,67 PM & 0 & 8.000 & 0 & 0 & 15.000 & $4.600(\mathrm{~b})$ \\
4.Biostat 50 WP & 150.000 & 32.000 & 17.500 & 1.000 & 24.000 & $44.900(\mathrm{a})$ \\
5.Testigo Absoluto & 61.000 & 35.000 & 30.000 & 6.000 & 58.000 & $38.000(\mathrm{ab})$ \\
\hline
\end{tabular}

*Letras diferentes tienen diferencias estadísticas entre tratamientos en la separación de medias según Tuckey al 5 \%

En el análisis de nematodos del suelo (Cuadro 10), se observó la presencia de los géneros fitoparásitos Meloidogyne sp. y Pratylenchus sp. Se destacó la presencia de larvas de Helicotylenchus sp. en el suelo y no en el tubérculo, esto es debido por ser un género ectoparásito, es decir su alimentación y ciclo de vida lo realiza no en las raíces de la planta.

Cuadro 10. Muestreo de $100 \mathrm{~g}$ de suelo en cada tratamiento en la cosecha Diamantes, Estación Experimental, Los Diamantes Guápiles. Costa Rica, Diciembre, 2005.

\begin{tabular}{cccccc}
\hline Tratamientos & $\begin{array}{c}\text { Meloido- } \\
\text { gyne sp. }\end{array}$ & $\begin{array}{c}\text { Helicotylen- } \\
\text { chus sp. }\end{array}$ & $\begin{array}{c}\text { Pratrylen- } \\
\text { chus sp. }\end{array}$ & Saprófitos & $\begin{array}{c}\text { Cricone- } \\
\text { moides sp. }\end{array}$ \\
\hline 1.Sincocin 0,55 SL & 150 & 100 & 50 & 475 & 50 \\
2.Microp 0,40 SL & 175 & 150 & 75 & 450 & 75 \\
3.Nemout 0,67 PM & 75 & 250 & 50 & 250 & 125 \\
4.Biostat 50 WP & 75 & 125 & 75 & 650 & 75 \\
5.Testigo Absoluto & 125 & 175 & 50 & 575 & 125 \\
\hline
\end{tabular}

En la Figura 1 se demostró, en la variable de nematodos en cáscara, que las poblaciones de Meloidogyne sp son bajas en tratamiento Microp 0,40 SL y altas en el tratamiento Nemout 0,67 PM. 


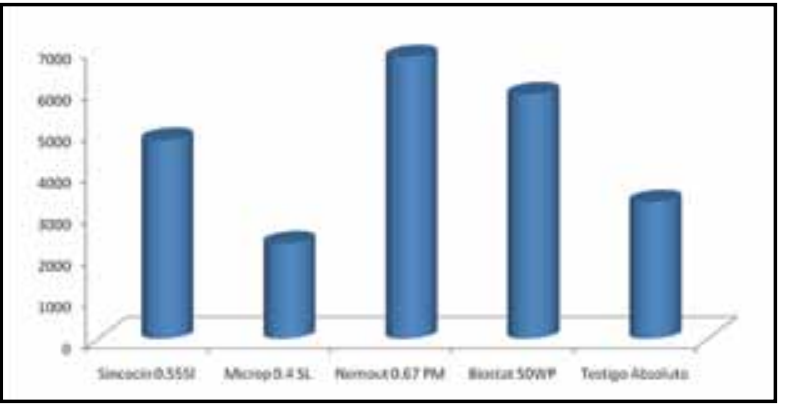

Figura 1. Población de Meloidogyne $s p$ en muestra de $100 \mathrm{~g}$ de cáscara de ñame (Dioscorea rotundata). Guápiles, Costa Rica. 2005.

En la Figura 2 el tratamiento Nemout 0,67 PM, con poblaciones bajas del género Pratylenchus $s p$ y altas en el tratamiento Biostat 50 WP. Esto es tomado como importante por ser dos géneros de importancia fitoparásito y también por la interacción con otros organismos que afectan la calidad y sanidad del tubérculo.

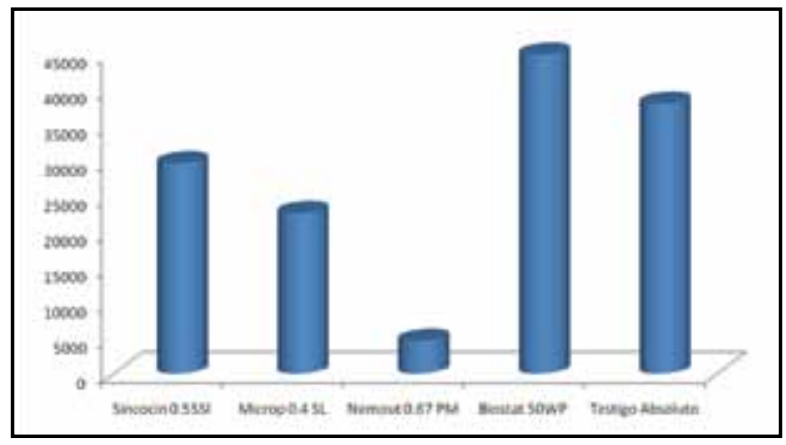

Figura 2. Población de Pratylenchus sp en muestra de $100 \mathrm{~g}$ de cáscara de ñame (Dioscorea rotundata). Guápiles, Costa Rica. 2005.

En el análisis de la cáscara de tubérculos de ñame se observó necrosis en su tejido (Figura 3), además, con tendencia a tener una podredumbre que dificultó la calidad del tubérculo, ya sea para comercialización o para la semilla en futuras siembras. Estos síntomas se observaron en todos los tratamientos, siendo el testigo absoluto más severo en su apariencia. El género de nematodo fitoparásito Pratylenchus $s p$, demostró, que produce en la cáscara del tubérculo agrietamiento y apariencia carbonosa, lo cual hace al tubérculo no aceptable en la siembra y la exportación.
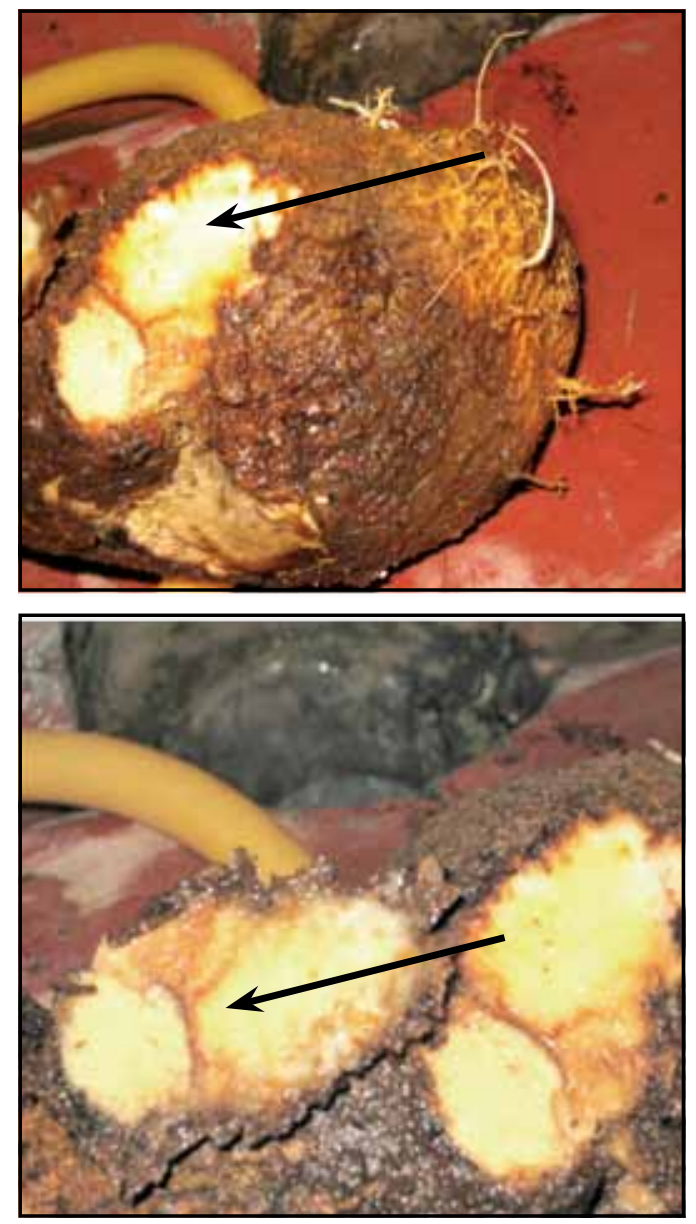

Figura 3. Tubérculos del testigo absoluto con daño de la interacción de nematodos fitoparásitos con otros microorganismos que afectaron el ñame (D. rotundata). Costa Rica. Diamantes. 2005. Fuente: INTA, Nematología.

\section{CONCLUSIONES}

Se determinó la presencia de tres géneros importantes de nematodos fitoparásitos en el cultivo de ñame, Meloidogyne sp., Helicotylenchus sp. y Pratylenchus sp.; este último es el más importante y el de mayor número de larvas en los $100 \mathrm{~g}$ de cáscara de ñame observados en tubérculos a la cosecha. 
El género Meloidogyne sp. presentó larvas en menor cantidad en los tratamientos Sincocin 0,55 SL y Microp 0,40 SL.

Se observó una población de Pratylenchus $s p$ más baja en los $100 \mathrm{~g}$ de cáscara de ñame en el tratamiento Nemout 0,67 PM, mientras que los demás tratamientos alcanzaron números mayores en la cáscara del tubérculo. Lo anterior indica que sí hubo eficacia biológica del nematicida Nemout 0,67 PM contra el género de nematodo fitoparásito Pratylenchus $s p$.

En el análisis estadístico, la variable peso en gramos de 4 plantas de ñame no se encontró diferencias significativas según Tukey al 5 $\%$. Los tratamientos presentaron un peso muy similar entre sí. El peso del tubérculo puede estar definido por varios factores entre los cuales puede existir disponibilidad de elementos nutricionales del suelo, concentración de minerales en el tubérculo y otros.

En el porcentaje de sanidad del tubérculo sí hubo diferencias estadísticas según Tukey al $5 \%$ en donde los mejores tratamientos fueron Sincocin 0,55 SL, Nemout 0,67 PM y Biostat 50 WP, por lo que estos tuvieron mejor sanidad, siendo éste último el que produjo más tubérculos sanos. Aunque existan diferencias estadísticas la sanidad del tubérculo puede estar definida por varios factores como: características de la variedad del tubérculo, elementos nutricionales del suelo, así como microorganismos tales como hongos y bacterias presentes en el suelo que han tenido un contacto con los tubérculos y afectan su apariencia.

En el análisis de nematodos de vida libre o saprófitos, las poblaciones encontradas tanto a la siembra como al final de la cosecha presentaron poblaciones importantes, por lo que estos organismos no fueron afectadas por los nematicidas biológicos. También esta importancia radica en que los nematodos de vida libre mantienen un equilibrio biológico y una buena relación de microorganismos, así como una buena distribución y descomposición de materiales minerales del suelo. Este aspecto hay que tomarlo en cuenta, ya que los nematicidas químicos generalmente bajan, o eliminan estas poblaciones, las cuales tienden a reponerse con el pasar del tiempo, provocando un desequilibrio de microorganismos.

Esta investigación evidenció que el problema de los nematodos fitoparásitos, Pratylenchus $s p$ y Meloidogyne sp, en el tubérculo de ñame requiere un manejo integrado del cultivo, donde no sólo se utilice un nematicida antes de la siembra; si no que, para su control, incluya todo el manejo de semilla y prácticas agronómicas del cultivo.

\section{RECOMENDACIONES}

Realizar muestreos de suelo antes de sembrar ñame (Dioscorea $s p$ ) para determinar la presencia de nematodos fitoparásitos. Esto ayudaría a tomar acciones en cuanto a tener o no que realizar una aplicación de nematicidas antes de la siembra.

Investigar y validar el nematicida Nemout 0,67 PM en parcelas con siembra de ñame para comprobar su efecto nematicida contra los géneros de nematodos fitoparásito Pratylenchus sp. y Meloidogyne sp.

En los muestreos de suelo valorar los nematodos de vida libre o saprófitos de suelo como un componente importante en el equilibrio de los microorganismos del suelo.

Analizar y valorar las causas de la interacción de los géneros Pratylenchus sp y Meloidogyne $s p$ con otros organismos patógenos del suelo y la relación con el efecto de la apariencia en la cáscara del tubérculo, tomando en cuenta si es para consumo interno o para la exportación. 


\section{LITERATURA CITADA}

Agrios, G. N. 1997. Plant Pathology. Fourth Edition. Academic Press. EUA. 635 p.

Aguilar, E. 1991. Aspectos Técnicos sobre cuarenta y cinco cultivos agrícolas de Costa Rica. Ministerio de Agricultura y Ganadería. Dirección General de Investigación y Extensión Agropecuaria. San José, Costa Rica. $485 \mathrm{p}$.

Beckman, C.H..1987. The Nature of Wilt Disease of plant. APS. The American Phytopathological St. Paul Minnesota. EUA. 58 p.

Melgar, C. M.. 2006. Guía del Cultivo de Ñame CV. Diamantes 22 Disponible en: http://www.infoagro.go.cr/tecnologia/ tuberculos/name.htm

Carballo M, G. 2004. Control Biológico de Plagas Agrícolas. CATIE, Turrialba, Cartago. Costa Rica. p. 186-195.

Crozzoli P, R. 1994. Temas de Nematología Agrícola. Universidad Central de Venezuela Facultad de Agronomía. Maracay, Venezuela. $15 \mathrm{p}$.

Pinochet, J. 1978. Histopathology of the root lesion nematode, Pratylenchus coffeae on plantains, Musa AAB. Nematológica. 24 p.

Ramírez, Álvaro. 1994. Gran Impacto de nematodos en el cultivo de café. Periódico la Nación p. 23-24.

Sanabria de Albarracín, N, 1994. Interacción entre nematodos y hongos causantes de Marchiteces. Instituto Botánico, Sección de Fitopatología, Facultad de Agronomía, Universidad Central de Venezuela. $57 \mathrm{p}$.

Institute. Cary, NC, 1989-1995. Statistical Analysis System. Version 6.11 New Carolina, EUA.

Taylor, A. L.; Loegering, W. Q. 1963. Nematodes associated with root lesions in abaca. Turrialba 3(1-3): 8-13. 
ALCANCES TECNOLÓGICOS, AÑO 6, NÚMERO 1 